\title{
Commentary: Anomalous left coronary artery from the pulmonary artery-Time is of the essence
}

\author{
Elizabeth H. Stephens, MD, PhD, and Joseph A. Dearani, MD
}

\author{
From the Department of Cardiovascular Surgery, Mayo Clinic, Rochester, Minn. \\ Disclosures: Authors have nothing to disclose with regard to commercial support. \\ Received for publication Oct 1, 2019; revisions received Oct 1, 2019; accepted for publication Oct 1, 2019; \\ available ahead of print Nov 9, 2019 \\ Address for reprints: Elizabeth H. Stephens, MD, PhD, Department of Cardiovascular Surgery, Mayo Clinic, 200 \\ First St SW, Rochester, MN 55905 (E-mail: stephens.elizabeth@mayo.edu). \\ J Thorac Cardiovasc Surg 2020;159:1953-4 \\ 0022-5223/\$36.00 \\ Copyright (C) 2019 by The American Association for Thoracic Surgery \\ https://doi.org/10.1016/j.jtcvs.2019.10.002
}

The cardiac surgeon learns early in her or his career that any type of coronary artery problem-congenital, acquired, or iatrogenic injury-can result in an unrecoverable situation in the operating room. Anomalous left coronary artery from the pulmonary artery (ALCAPA) is unique in that significant systolic dysfunction at the time of presentation is often present and is not responsive to conventional resuscitative maneuvers. Early surgery with establishment of a dual coronary system involving reimplantation of the left coronary artery into the aorta is the procedure of choice.

The study by Zhang and colleages ${ }^{1}$ published in this issue of the Journal reviewed 105 patients who underwent ALCAPA repair at their institution during a 10-year period. A unique feature of their study, and their key contribution to our current understanding of ALCAPA, is their working within a health care environment and referral pattern of China in which many patients were diagnosed relatively late. The median age at repair was 7.6 months, which is 2 to 3 months older than many previous large studies of ALCAPA, ${ }^{2-4}$ and only $10 \%$ of their cohort were younger than 3 months. Zhang and colleages ${ }^{1}$ were able to identify subgroups with significantly higher risk of mortality relative to the remainder of the cohort: those with moderate depression in preoperative left-ventricular ejection fraction (LVEF) to $\leq 42 \%$, but more significantly those with LVEF of $\leq 42 \%$ who also were older than 4 months of age. Although the study does not specify the number of patients older than 4 months who had a preoperative LVEF $>42 \%$, one would anticipate that this number would be relatively few. Nevertheless, the mortality for those patients older than 4 months with LVEF of $\leq 42 \%(n=25)$ was dreadfully high $(52 \%)$ ! Furthermore, patients within this high-risk group who did survive demonstrated lower LVEF in the long term relative to the other groups (LVEF of $42 \%$ or less with age younger than 4 months and LVEF $>42 \%$ ). Clearly, this finding emphasizes the importance of improving the timely diagnosis and early surgical referral of a relatively rare disease that requires a high index

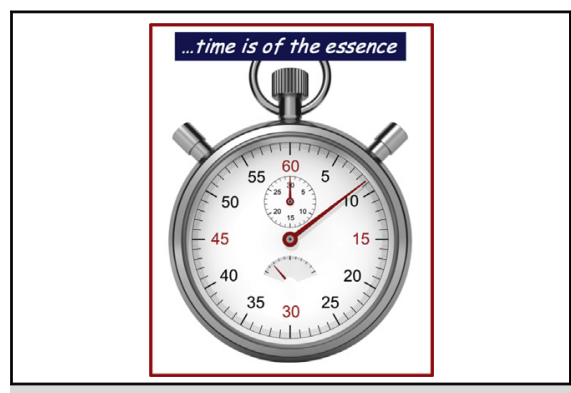

Time is of the essence in anomalous left coronary artery from the pulmonary artery.

\section{Central Message}

Early diagnosis of anomalous left coronary artery from the pulmonary artery with immediate surgery has the best early and late outcomes.

See Article page 1945.

of suspicion. The groundwork for such changes involves the essentials of perceptive health care professionalscardiologists, pediatricians, intensivists, nurse practitioners and, yes, surgeons - to think critically and include ALCAPA in the differential diagnosis of an infant with heart failure symptoms (tachypnea, failure to thrive). As demonstrated in this study, earlier diagnosis substantially impacts the ability of the surgeon to care for these babies effectively, and, more importantly, the short- and longterm prognosis for the patients themselves.

The other important finding of this study that deserves comment is the role and effect of mechanical circulatory support (MCS). In the experience of Zhang and colleages, ${ }^{1}$ before 2013 MCS was rarely used (only 1 patient) before 2013, and 7 patients died secondary to ventricular fibrillation. After 2013, 15 patients were placed on MCS; 9 in the operating room and 6 in the immediate postoperative period. Of these, 10 survived, with 1 neurologic injury in the cohort. The key risk factor for MCS was LVEF of $\leq 30 \%$; the majority $(73 \%)$ of patients in that group required MCS. In a health care environment in which diagnosis and referral is delayed, MCS can be a lifesaver.

Other aspects of this study reinforce findings from other reports: specifically, low LVEF has a worse prognosis, LVEF improves after surgery, ${ }^{2,6-8}$ and mitral regurgitation improves after ALCAPA repair. ${ }^{2,4,8}$ In the current study of Zhang and colleages, ${ }^{1}$ after a transient postoperative 
decrease, the LVEF normalized by 2 weeks postoperatively; however, patients with LVEF of $\leq 42 \%$ and an $>4$ months had normalization to LVEF of only approximately $50 \%$, significantly lower than in the other groups, as discussed previously. This persistent low-normal LVEF contradicts reports by other authors, who believe that normalization of LVEF occurs independent of age after ALCAPA repair. ${ }^{2}$

The role of mitral valvuloplasty at the time of ALCAPA repair remains controversial ${ }^{2,6-9}$ and is not addressed in the current study. On the basis of surgeon preference, all patients with severe preoperative mitral regurgitation underwent mitral repair; however, patients with moderate mitral regurgitation who did not undergo a mitral intervention did show improvement in the degree of regurgitation consistent with previous studies. ${ }^{6-9}$ Others have found that $5 \%$ to $15 \%$ of patients with preoperative mitral regurgitation not intervened on at the time of ALCAPA repair require a late mitral valve intervention at 10 to 15 years; however, those studies were in younger patient populations and may not apply to the current study. ${ }^{2,4}$

The remarkable regenerative abilities of the infantile myocardium in the first few months of life emphasize the importance of early diagnosis of ALCAPA by astute clinicians, followed by immediate surgery. So, what is the take-home message from this article? Time is of the essence with ALCAPA! Diagnose and Godspeed to the operating room!

\section{References}

1. Zhang W, Hu R, Zhu Y, Zhang W, Yu X, Sun Y, et al. Surgical outcomes for anomalous left coronary artery from the pulmonary artery: impact of late presentation. $J$ Thorac Cardiovasc Surg. 2020;159:1945-52.e1.

2. Lange R, Cleuziou J, Krane M, Ewert P, Pabst von Ohain J, Beran E, et al. Longterm outcome after anomalous left coronary artery from the pulmonary artery repair: a 40-year single-centre experience. Eur J Cardiothorac Surg. 2018;53:732-9.

3. Weigand J, Marshall CD, Bacha EA, Chen JM, Richmond ME. Repair of anomalous left coronary artery from the pulmonary artery in the modern era: preoperative predictors of immediate postoperative outcomes and long term cardiac follow-up. Pediatr Cardiol. 2015;36:489-97.

4. Naimo PS, Fricke TA, d'Udekem Y, Cochrane AD, Bullock A, Robertson T, et al. Surgical intervention for anomalous origin of left coronary artery from the pulmonary artery in children: a long-term follow-up. Ann Thorac Surg. 2016;101: 1842-8.

5. Lange R, Vogt M, Hörer J, Cleuziou J, Menzel A, Holper K, et al. Long-term results of repair of anomalous origin of the left coronary artery from the pulmonary artery. Ann Thorac Surg. 2007;83:1463-71.

6. Ling Y, Bhushan S, Fan Q, Tang M. Midterm outcome after surgical correction of anomalous left coronary artery from the pulmonary artery. J Cardiothorac Surg. 2016;11:137.

7. Patel SG, Frommelt MA, Frommelt PC, Kutty S, Cramer JW. Echocardiographic diagnosis, surgical treatment, and outcomes of anomalous left coronary artery from the pulmonary artery. J Am Soc Echocardiogr. 2017;30:896-903.

8. Mongé MC, Eltayeb O, Costello JM, Sarwark AE, Carr MR, Backer CL. Aortic implantation of anomalous origin of the left coronary artery from the pulmonary artery: long-term outcomes. Ann Thorac Surg. 2015;100:154-60; discussion 160-1.

9. Zhang HL, Li SJ, Wang X, Yan J, Hua ZD. Preoperative evaluation and midterm outcomes after the surgical correction of anomalous origin of the left coronary artery from the pulmonary artery in 50 infants and children. Chin Med J (Engl). 2017; 130:2816-22. 